\title{
Endogenous Opiates Modulate the Pulsatile Secretion of Biologically Active Luteinizing Hormone in Man
}

\author{
Johannes D. Veldhuis, Alan D. Rogol, and Michael L. Johnson, Division of \\ Clinical Pharmacology, Department of Pediatrics, Department of \\ Pharmacology, Division of Endocrinology and Metabolism, Department of \\ Internal Medicine, Section of Human Reproductive Medicine, Department \\ of Obstetrics and Gynecology, and Biomathematics Core Laboratory of the \\ Diabetes Research and Training Center, The University of Virginia Medical \\ Center, Charlottesville, Virginia 22908
}

\author{
Maria L. Dufau, Section on Molecular Endocrinology, Endocrinology and \\ Reproduction Research Branch, National Institute of Child Health and \\ Human Development, National Institutes of Health, Bethesda, Maryland \\ 20205
}

A B S T R A C T We studied the secretion of physiological pools of immunoreactive and biologically active luteinizing hormone in response to endogenous pulses of gonadotropin-releasing hormone (GNRH) in eugonadal men. Concentrations of immunoactive and bioactive luteinizing hormone ( $\mathrm{LH})$ were determined in blood drawn at 20-min intervals for $8 \mathrm{~h}$ in eight normal men under two conditions: (a) after placebo, in order to evaluate spontaneous $\mathrm{LH}$ pulsations in the basal state, and $(b)$ after administration of the opiate-receptor antagonist, naltrexone, which is believed to amplify the pulsatile release of endogenous GNRH. Spontaneous and naltrexone-stimulated secretion of $\mathrm{LH}$ occurred in pulses of high biological activity, as measured in the RICT (rat interstitial cell testosterone bioassay), i.e., bioactive:immunoactive $\mathrm{LH}$ ratios within both spontaneous and naltrexone-stimulated $\mathrm{LH}$ pulses were higher than corresponding interpulse ratios $(P<0.001)$.

This work was presented in part at the National Meeting of the American Society for Clinical Investigation, Washington, DC, 1982.

This work was supported in part by a Research Career Development Award AM 00153 to Dr. Rogol, by National Institutes of Health Biomedical Research Support Award 5S07RR05431 and a University of Virginia Computer Services grant and National Institute of Drug Abuse grant 1R03DA03315-01 to Dr. Veldhuis. Address all correspondence to Dr. Veldhuis, Department of Internal Medicine, University of Virginia Medical School.

Received for publication 17 February 1983 and in revised form 9 August 1983.
Quantitative characterization of the pulsatile release of bioactive $\mathrm{LH}$ revealed the following specific effects of opiate-receptor blockade: increased 8-h mean and integrated serum concentrations of bioactive $\mathrm{LH}(P$ $<0.002$ ), enhanced pulse frequency of bioactive LH release $(P<0.001)$, and augmented peak amplitude of bio-LH pulses $(P<0.01)$. Moreover, this increase in episodic secretion of bioactive $\mathrm{LH}$ was associated with increased 8-h mean and integrated serum testosterone concentrations in these men $(P<0.05)$.

We conclude the following: (a) LH is normally released in spontaneous pulses of high biological activity in men; (b) when the endogenous GNRH signal is amplified by opiate-receptor blockade, the pituitary gland releases more frequent bioactive LH pulses, which are of high amplitude and contain a high bioactive:immunoactive $\mathrm{LH}$ ratio. This increase in pulsatile release of bioactive LH quantitated in the RICT assay in vitro is reflected by acutely increased serum testosterone concentrations in vivo. We infer that modulation of the episodic GNRH signal by endogenous opiates provides another significant mechanism by which the hypothalamus can alter the biological activity of circulating gonadotropic hormone in man. Moreover, observed alterations in the pulsatile pattern of bioactive LH release were associated in turn with significant changes in testosterone concentrations. Thus, we hypothesize that alterations in the properties of the bioactive LH pulse signal can provide an important mechanism for regulating target-cell function within the gonad in states of health or disease. 


\section{INTRODUCTION}

Luteinizing hormone $(\mathrm{LH})^{1}$ is normally secreted in an episodic fashion. In most studies to date, this pulsatile pattern of LH release has been characterized solely in terms of LH immunoactivity (1-9). More recently, we have demonstrated prominent high amplitude, low frequency pulses of biologically active LH in the human circulation (10). On the basis of studies in experimental animals, intermittent fluctuations in circulating (immunoactive) $\mathrm{LH}$ concentrations are believed to reflect pituitary stimulation by corresponding pulses of endogenous gonadotropin-releasing hormone (GNRH) $(11,12)$. Exogenously administered GNRH can also promote pituitary release of both immunoactive and bioactive LH (13-15). However, preferential release of pool(s) of LH enriched in biological activity has been difficult to demonstrate in man, whether singlebolus or continuous low dose infusions of GNRH have been used $(14,15)$. Thus, alternative experimental approaches are required to characterize the physiological release of functional pools of immunoactive and bioactive LH in man. Such approaches could include either mimicking the physiological mode of endogenous GNRH secretion by infusing exogenous GNRH in discrete pulses, or enhancing the endogenous generation of GNRH pulses.

In the present work we have used an opiate-receptor antagonist to amplify the endogenous GNRH signal for LH release. Prior investigations in experimental animals and in man indicate that opiate-receptor antagonists stimulate pulsatile secretion of immunoactive $\mathbf{L H}$ by disinhibiting brain mechanisms that otherwise suppress GNRH secretion (16-21). By blocking the endogenous opiate system, we have been able to characterize the release of physiological pools of immunoactive and bioactive $\mathrm{LH}$ in response to endogenously generated GNRH pulses in normal man, and test the impact of an altered LH signal on testosterone production.

\section{METHODS}

Studies were conducted in eight healthy normal male volunteers (age range from 24 to $35 \mathrm{yr}$ ), who had normal serum concentrations of free thyroxine, prolactin, immunoactive $\mathrm{LH}$ and follicle-stimulating hormone, free testosterone, and $17 \beta$-estradiol. Each subject provided written informed consent before participation.

Blood samples were collected at 20-min intervals for $8 \mathrm{~h}$ beginning $60 \mathrm{~min}$ after oral ingestion of placebo elixir or naltrexone $(1 \mathrm{mg} / \mathrm{kg})$ at 0800 on separate days. Plasma samples were assayed for immunoactive LH by a double-antibody

\footnotetext{
${ }^{1}$ Abbreviations used in this paper: GNRH, gonadotropinreleasing hormone; hMG, human menopausal gonadotropin; LH, luteinizing hormone; RICT, rat interstitial-cell testosterone bioassay.
}

radioimmunoassay (22), with a sensitivity of $1 \mathrm{mIU} / \mathrm{ml}$ in terms of the 2nd International Reference Preparation of human Menopausal Gonadotropin (hMG); and for bioactive LH, by rat interstitial cell testosterone assay (RICT) $(23,24)$ with a sensitivity of $0.4 \mathrm{mIU} / \mathrm{ml}$, or $3 \mathrm{pg}$ of pure LH (LER 1533). The intraassay coefficient of variation for the bioassay was 8.3\% (computed from 13 replicates) and for the immunoassay, $8.8 \%$. The potency of the purified preparation in terms of the hMG standard was very similar when measured by bioassay or by RIA, namely, $13,500(11,200-15,200)$ and 13,700 $(11,100-14,900) \mathrm{IU} / \mathrm{mg}$, respectively. Thus, the bioimmunoactive ratio of plasma samples calculated for LH measured in terms of $\mathrm{hMG}$ or pure $\mathrm{LH}$. is very similar. The serum testosterone concentration was measured in each sample by radioimmunoassay (25), after diethyl ether extraction and celite chromatography. In one subject, there was insufficient blood for serum immunoactive $\mathrm{LH}$ and testosterone assays, so that only bioactive $\mathrm{LH}$ was measured.

The plasma LH secretion profiles were analyzed for significant fluctuations by the computerized pulse-detection algorithm of Clifton and Steiner (26) and Steiner et al. (27). This method performs iterative data scans to identify significant fluctuations (pulses) that exceed a threshold value, which is initially estimated as 2.7 times the within-assay coefficient of variation. Iteration with threshold adjustment is continued until the probability of obtaining a false pulse equals the probability of missing a true pulse $(26,27)$. The frequency (number of pulses per sampling interval) and incremental amplitude (nadir-to-peak increases in LH concentration, expressed in milli International Units per milliliter) of pulses can be estimated in the presence of random measurement errors (noise). When a single prominent LH pulse was apparent (amplitude exceeding that of other $\mathrm{LH}$ pulses by $>50 \%$ ), the data were rescanned after omission of the dominant pulse in order to obviate damping of the residual pulse signals. In addition, the program was modified to display the individual significant increases and decreases (pulses) detected, which were then enumerated. For each analysis, an estimate of the pulse signal-to-noise ratio is also given, which in the present studies exceeded 2.5. Bioactive and immunoactive $\mathrm{LH}$ pulses were considered concordant whenever the point (or points) inscribed above base line within the pulses overlapped in time. The area under the LH concentration-vs.-time curve, and the fractional amplitude of significant pulses (given as percentage above preceding nadir) were also computed with the program of Santen and Bardin (28). Pulse data are given as means $\pm S D$, and were analyzed by within-subject comparisons using a paired, two-tailed $t$ test (29). To test the hypothesis that increased bioimmunoactive $\mathrm{LH}$ ratios occurred preferentially within bioactive LH peaks, nonparametric analysis was applied. In any given subject, the number of bioimmunoactive $\mathrm{LH}$ ratios above the median was determined both in bioactive $\mathrm{LH}$ pulses and in the corresponding interpulse base line. A $\chi^{2}$ table was constructed to analyze the expected vs. observed distribution of increased bioimmuno ratios (29).

\section{RESULTS}

Bioactive $L H$. In the basal state (after placebo administration), bioactive $\mathrm{LH}$ was secreted in prominent pulses having a mean amplitude of $14.6 \pm 6.34 \mathrm{mIU} /$ $\mathrm{ml}$ above preceding nadir, with mean absolute peak levels of $38.6 \pm 13.2 \mathrm{mIU} / \mathrm{ml}$ (see Table I). The fractional increase of bioactive $\mathrm{LH}$ in these pulses was $73 \pm 35 \%$ 
TABLE I

Pulsatile Secretion of Bioactive LH in Man

\begin{tabular}{|c|c|c|c|c|c|c|c|c|}
\hline Subject & Treatment & Mean $\mathrm{LH}^{\bullet}$ & Areal & Pulses $/ 8 \mathrm{~h}$ & Incremental§ & Peak" & $\begin{array}{c}\text { Fractional } \\
(\%) \pi\end{array}$ & $\begin{array}{c}\text { Mean } \\
\text { periodicity.• }\end{array}$ \\
\hline \multirow[t]{2}{*}{ A } & Placebo & $13.71 \pm 4.96$ & 6,623 & 2 & 14.0 & 25.9 & 80 & 220 \\
\hline & Naltrexone & $14.16 \pm 3.07$ & 6,850 & 5 & 7.3 & 18.9 & 65 & 100 \\
\hline \multirow[t]{2}{*}{ B } & Placebo & $24.86 \pm 7.02$ & 11,992 & 3 & 12.1 & 30.3 & 87 & 180 \\
\hline & Naltrexone & $29.21 \pm 7.59$ & 14,101 & 4 & 24.2 & 42.2 & 72 & 125 \\
\hline \multirow[t]{2}{*}{$\mathrm{C}$} & Placebo & $10.50 \pm 3.43$ & 5,032 & 2.5 & 9.8 & 17.2 & 149 & 200 \\
\hline & Naltrexone & $19.64 \pm 7.08$ & 9,644 & 6 & 13.4 & 27.4 & 92 & 63 \\
\hline \multirow[t]{2}{*}{ D } & Placebo & $38.77 \pm 6.27$ & 18,682 & 3 & 15.0 & 43.8 & 55 & 180 \\
\hline & Naltrexone & $47.38 \pm 7.84$ & 22,968 & 4.5 & 17.2 & 57.2 & 65 & 115 \\
\hline \multirow[t]{2}{*}{$\mathbf{E}$} & Placebo & $33.90 \pm 6.57$ & 17,041 & 2 & 19.6 & 46.3 & 39 & 220 \\
\hline & Naltrexone & $46.64 \pm 11.86$ & 22,588 & 4 & 16.9 & 59.8 & 69 & 125 \\
\hline \multirow[t]{2}{*}{$\mathbf{F}$} & Placebo & $30.86 \pm 3.47$ & 14,820 & 1 & 5.9 & 39.6 & 38 & - \\
\hline & Naltrexone & $36.40 \pm 7.41$ & 17,564 & 3 & 23.6 & 47.0 & 63 & 180 \\
\hline \multirow[t]{2}{*}{ G } & Placebo & $40.62 \pm 17.4$ & 19,657 & 3 & 28.2 & 60.1 & 79 & 180 \\
\hline & Naltrexone & $42.92 \pm 15.6$ & 20,479 & 5.5 & 29.3 & 61.4 & 110 & 100 \\
\hline \multirow[t]{2}{*}{$\mathbf{H}$} & Placebo & $16.21 \pm 5.43$ & 7,877 & 2 & 12.1 & 29.3 & 57 & 220 \\
\hline & Naltrexone & $28.23 \pm 8.06$ & 13,550 & 3 & 24.0 & 41.4 & 70 & 180 \\
\hline \multirow[t]{4}{*}{ Means \pm SD } & Placebo & $26.18 \pm 10.90$ & 12,175 & 2.31 & 14.6 & 38.6 & $73 \pm 34$ & $200 \pm 19$ \\
\hline & & & $\pm 5,327$ & \pm 0.66 & \pm 6.34 & \pm 13.2 & & \\
\hline & Naltrexone & $33.07 \pm 11.5$ & 15,954 & 4.375 & 19.5 & 44.4 & $76 \pm 16$ & $124 \pm 37$ \\
\hline & & & $\pm 5,583$ & \pm 1.02 & \pm 6.64 & \pm 14.4 & & \\
\hline \multicolumn{9}{|l|}{$P$ value } \\
\hline \multicolumn{2}{|c|}{ (Placebo vs. Naltrexone) } & $<0.001$ & $<0.002$ & $<0.001$ & NS & $<0.01$ & NS & $<0.002$ \\
\hline
\end{tabular}

- $\mathrm{mIU} / \mathrm{ml}$, mean $\pm \mathrm{SD}$ ( $n=25$ samples).

† Area in $\mathrm{mIU} / \mathrm{ml} \times$ min (over $8 \mathrm{~h}$ of sampling).

$\$ \mathrm{mIU} / \mathrm{ml}$ increment from nadir to peak.

"Maximal absolute $\mathrm{LH}$ value achieved in the pulse $(\mathrm{mIU} / \mathrm{ml})$.

I Percentage increase above nadir.

$\because$ Minutes.

above preceding base line. There were $2.31 \pm 0.66$ bioactive LH pulses per $8 \mathrm{~h}$. The mean (and integrated) serum bioactive LH levels are very similar to those previously reported in other healthy men $(10,14$, and 15).

After naltrexone administration, there was a highly significant increase in mean serum bioactive $\mathrm{LH}$ levels from $26.2 \pm 10.9$ to $33.1 \pm 11.5 \mathrm{mIU} / \mathrm{ml}(P<0.001)$, with a corresponding increase in integrated concentrations of bioactive LH $(P<0.002$, see Table I). Treatment with this opiate-receptor antagonist also significantly enhanced the frequency of bioactive $\mathrm{LH}$ pulses from $2.31 \pm 0.66$ to $4.38 \pm 1.0$ pulses $/ 8 \mathrm{~h}(P<0.001)$, and augmented the absolute peak $\mathrm{LH}$ values attained within individual pulses from $38.6 \pm 13.2$ to $44.4 \pm 14.4$ $\mathrm{mIU} / \mathrm{ml}(P<0.01$ treatment effect $)$. Neither the frac- tional (percentage above base line) nor the incremental (milli International Units per milliliter above preceding nadir) amplitude of bioactive LH pulses was altered (Table I). In accord with the increase in LH pulse frequency, there was a corresponding significant decrease in the mean periodicity of bioactive $\mathrm{LH}$ pulses from $200 \pm 19 \mathrm{~min}$ (basal) to $124 \pm 37 \mathrm{~min}$, after naltrexone $(P<0.002)$. None of these effects could be attributed to interfering properties of naltrexone in the bioassay, since naltrexone was inactive in the RICT at concentrations $(10 \mathrm{ng} / \mathrm{ml}$ and $50 \mathrm{ng} / \mathrm{ml})$ equal and exceeding those attained in plasma $(10 \mathrm{ng} / \mathrm{ml}[30,31])$. (Table II). In addition, naltrexone did not alter the signal-to-noise ratio for the pulse detection methodology (the mean signal-to-noise ratio was $3.28 \pm 0.28$ after placebo, and $3.54 \pm 0.26$ after naltrexone). These signal- 
TABLE II

Basal and Gonadotropin-stimulated Testosterone Production by Leydig Cells In Vitro: Lack of Effect of Naltrexone or Vehicle on the RICT Assay

\begin{tabular}{lcrl}
\hline \multicolumn{1}{c}{ Experimental } & $\begin{array}{c}\text { IncubationthMG } \\
(0.625 \mathrm{mIU})\end{array}$ & Mean & 土SE \\
\hline 1. Control assay & - & 8.9 & 0.34 \\
& + & 50.2 & 0.49 \\
2. In presence of vehicle: & - & 9.3 & 0.85 \\
& - & 9.7 & 0.33 \\
& + & 49.1 & 1.0 \\
3. In presence of naltrexone: & + & 48.9 & 0.79 \\
& - & 9.1 & 0.8 \\
& - & 8.9 & 0.50 \\
& + & 49.7 & 0.8 \\
& + & 50.6 & 0.69 \\
\hline
\end{tabular}

Naltrexone concentrations used in the in vitro incubations are equivalent to circulating levels of 10 and $50 \mu \mathrm{g} /$ liter (31). An equivalent volume of vehicle was used in separate incubations.

to-noise ratios are well within the range of accurate pulse detection for this computer algorithm (26).

Immunoactive $L H$. Immunoactive $\mathrm{LH}$ concentrations were also measured for each of the 20-min samples drawn over $8 \mathrm{~h}$ in seven men. The changes in serum immunoactive $\mathrm{LH}$ levels basally and after naltrexone were similar qualitatively to those described above for bioactive $\mathrm{LH}$. Mean serum immunoactive $\mathrm{LH}$ concentrations rose from $8.6 \pm 2.61 \mathrm{mIU} / \mathrm{ml}$ basally to $12.2 \pm 5.6$ $\mathrm{mIU} / \mathrm{ml}$ after naltrexone administration $(P<0.02)$, and integrated $\mathrm{LH}$ concentrations increased from $4,120 \pm 1,330$ basally to $5,828 \pm 2,680 \mathrm{mIU} / \mathrm{ml} x \mathrm{~min}$ after drug $(P<0.02)$. Naltrexone also significantly increased the frequency of $\mathrm{LH}$ pulses from $3.22 \pm 0.6$ basally to $4.57 \pm 0.7$ pulses $/ 8 \mathrm{~h}(P<0.008)$, and increased mean absolute peak immunoactive $\mathrm{LH}$ values from $12.8 \pm 3.5$ to $16.0 \pm 5.6 \mathrm{mIU} / \mathrm{ml}$ after naltrexone administration $(P<0.02)$. There was a corresponding significant decline in pulse periodicity from $166 \pm 37$ to $112 \pm 16 \mathrm{~min} /$ pulse $(P<0.009)$, with no significant alteration in incremental or fractional (percentage) amplitude of immunoactive $\mathrm{LH}$ pulses.

Representative profiles of serum bioactive and immunoactive LH are given for three men in Fig. 1. When all data were separately analyzed by the method of Santen and Bardin (5), LH pulses detected agreed well with those of the method of Clifton and Steiner (26) $(82.5 \%$ concordance). The small discrepancy reflects the different cut-off criteria used $(5,26)$.

Comparison of bioactive and immunoactive $L H$. Bioactive LH pulses were concordant with immunoactive LH pulses in $83 \%$ of cases overall, i.e., 38 of
46 bioactive $\mathrm{LH}$ pulses were associated with coincident immunoactive LH pulses. There was a somewhat greater discordance for immunoactive pulses than for bioactive pulses, i.e., 17 of 57 or $29 \%$ of immunoactive LH peaks were not associated with a corresponding increase in bioactivity, while 8 of 46 or $17 \%$ of bioactive LH peaks did not have a coincident increase in immunoactivity. These values are similar to those we described previously (10). When analyzed further, neither concordance nor discordance of immunoactive and bioactive LH pulses was affected by naltrexone compared with placebo administration.

Bioactive:immunoactive LH ratios fluctuated over time after placebo ingestion (spontaneous) and after naltrexone administration. After placebo ingestion, spontaneous increases in bioactive:immunoactive $\mathbf{L H}$ ratios occurred significantly more commonly within bioactive LH peaks, than in the interpulse base line $(P<0.001$, Table III, $A)$. Similarly, after naltrexone administration, increases in bioactive:immunoactive $\mathrm{LH}$ ratios also occurred significantly more often within bioactive $\mathrm{LH}$ pulses, than in the corresponding interpulse base line $(P<0.001$, Table III, $B)$. In particular, the mean $( \pm S D)$ values of the bioactive:immunoactive LH ratios within bioactive $\mathrm{LH}$ pulses were $5.27( \pm 3.60)$ for placebo and $4.44( \pm 1.88)$ for naltrexone, which compare with corresponding interpulse base-line ratios of $3.26( \pm 1.65)$ and $3.48( \pm 1.5)$ for placebo and naltrexone, respectively.

Compared with placebo, administration of naltrexone did not significantly influence overall bioactive:immunoactive $\mathrm{LH}$ ratios $(3.84 \pm 1.71$ for placebo, $3.72 \pm 1.66$ for naltrexone). Moreover, compared with placebo, naltrexone did not curtail the preferential distribution of increased bioactive:immunoactive $\mathrm{LH}$ ratios within bioactive LH pulses (Table III, C). Thus, after naltrexone administration the same significant tendency for increased bioactive:immunoactive $\mathrm{LH}$ ratios to occur preferentially within bioactive LH pulses was observed.

Serum testosterone concentrations. The serum testosterone concentration was measured in each sample collected at 20-min intervals for $8 \mathrm{~h}$. Mean serum testosterone increased significantly after naltrexone administration, i.e., from $570 \pm 151 \mathrm{ng} / \mathrm{dl}$ basally, to $645 \pm 120 \mathrm{ng} / \mathrm{dl}$ after drug ingestion $(P<0.05$ withinsubject treatment effect). The integrated areas under the testosterone concentration-vs.-time curves also increased significantly $(P<0.05)$. Data for individual men are given in Fig. 2.

When pulse analysis was applied to the serial testosterone values, we were unable to define any facile relationship between fluctuating testosterone levels (average of $3.5 \pm 1.0$ peaks $/ 8 \mathrm{~h}$ ) and preceding bioactive or immunoactive LH peaks. Examination of the profiles 

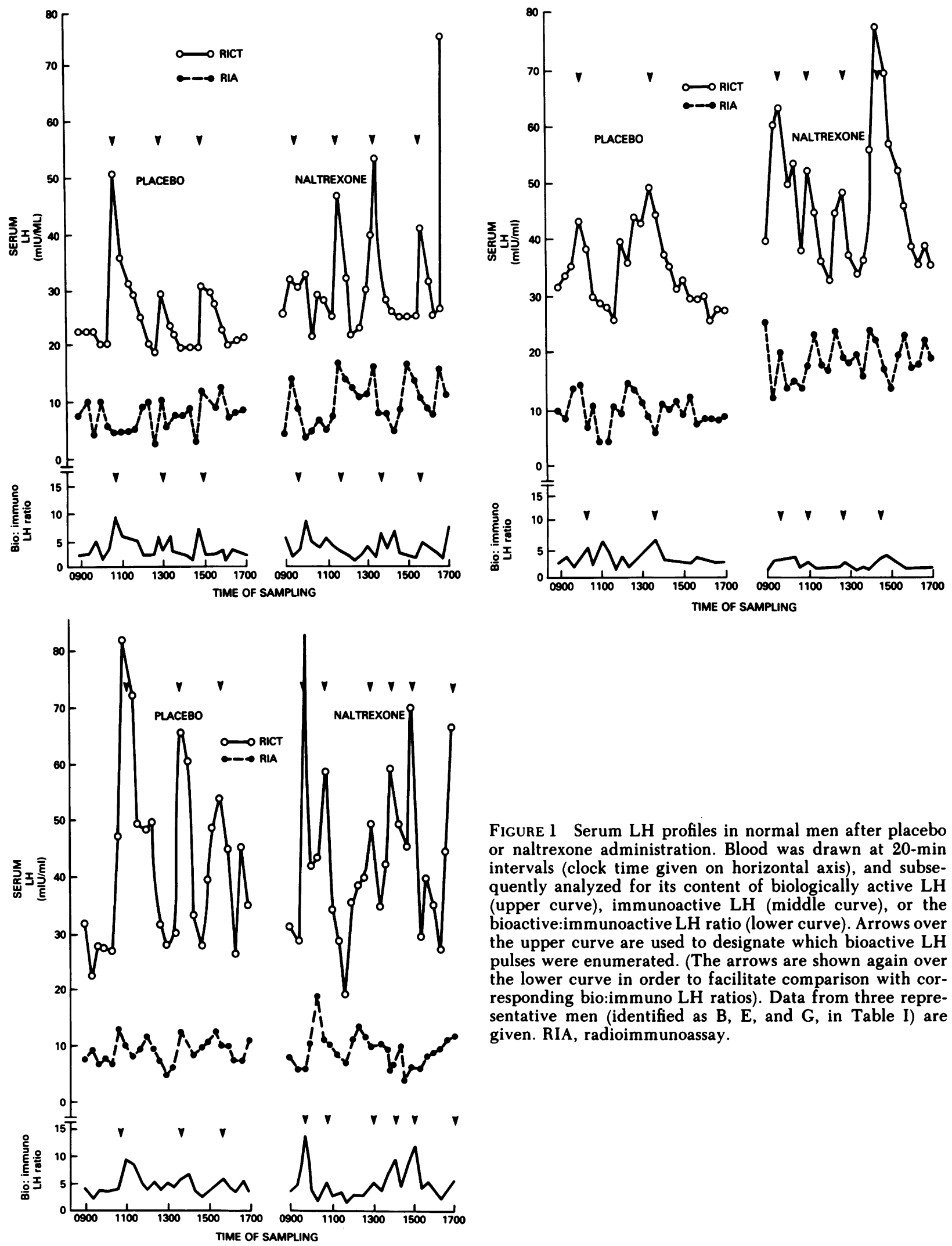

Figure 1 Serum LH profiles in normal men after placebo or naltrexone administration. Blood was drawn at 20-min intervals (clock time given on horizontal axis), and subsequently analyzed for its content of biologically active LH (upper curve), immunoactive LH (middle curve), or the bioactive:immunoactive $\mathrm{LH}$ ratio (lower curve). Arrows over the upper curve are used to designate which bioactive LH pulses were enumerated. (The arrows are shown again over the lower curve in order to facilitate comparison with corresponding bio:immuno $\mathrm{LH}$ ratios). Data from three representative men (identified as $B, E$, and $G$, in Table I) are given. RIA, radioimmunoassay. 
TABLE III

LH Bioactive:Immunoactive Ratios in Eugonadal Men

\begin{tabular}{|c|c|c|c|c|c|c|}
\hline & \multicolumn{2}{|c|}{ A. Spontaneous (placebo) } & \multicolumn{2}{|c|}{ B. After naltrexone administration } & & \\
\hline & \multirow{2}{*}{$\begin{array}{c}\text { Within-pulse } \\
\text { bioactive:immunoactive } \\
\text { ratios }\end{array}$} & \multirow{2}{*}{$\begin{array}{c}\text { Interpulse } \\
\text { bioactive:immunoactive } \\
\text { ratios }\end{array}$} & \multirow{2}{*}{$\begin{array}{c}\text { Within-pulse } \\
\text { bioactive:immunoactive } \\
\text { ratios }\end{array}$} & \multirow{2}{*}{$\begin{array}{c}\text { Interpulse } \\
\text { bioactive:immunoactive } \\
\text { ratios }\end{array}$} & \multicolumn{2}{|c|}{ C. Within bioactive LH pulse } \\
\hline & & & & & Placebo & Naltrexone \\
\hline \multirow{2}{*}{$\begin{array}{l}\text { Number of } \\
\text { bioactive:immunoactive } \\
\text { ratios }>\text { median }\end{array}$} & 38 & 51 & 44 & 35 & 34 & 44 \\
\hline & $\overline{(24.29)}$ & $\overline{(64.08)}$ & $\overline{(27.54)}$ & $\overline{(51.46)}$ & $\overline{(35.89)}$ & $\overline{(42.11)}$ \\
\hline \multirow{2}{*}{$\begin{array}{l}\text { Number of } \\
\text { bioactive:immunoactive } \\
\text { ratios } \leq \text { median }\end{array}$} & 18 & 93 & 17 & 79 & 18 & 17 \\
\hline & $\begin{aligned} & (31.08) \\
\chi^{2} & =17.181 \\
P & <0.001\end{aligned}$ & $(79.92)$ & $\begin{array}{c}(33.46) \\
\chi^{2}=27.53 \\
P<0.001\end{array}$ & $(62.53)$ & $\begin{array}{c}(16.11) \\
\chi^{2}=0.595 \\
P<0.384\end{array}$ & $(\mathbf{1 8 . 8 9})$ \\
\hline
\end{tabular}

Expected values are given in parentheses.

of serial testosterone levels and LH peaks in these men indicated that bioactive LH peaks occasionally (but not invariably) preceded increases in testosterone (see Discussion).

Serum prolactin concentrations. In five men, mean or integrated serum prolactin concentrations measured at 20-min intervals for $8 \mathrm{~h}$ were not influenced by naltrexone (data not shown), indicating the absence of any discernible opiate-agonist effect of this drug under these conditions.

\section{DISCUSSION}

In the present work, we have explored the mode of release of physiological pools of immunoactive and bioactive $\mathrm{LH}$ in response to endogenous pulses of GNRH in eugonadal men. First, we have formally presented the novel observation that LH secretion in the adult male occurs in spontaneous pulses of high biological activity, reflected in episodically increased bioactive:immunoactive LH ratios within LH pulses compared with interpulse base-line ratios (10). Secondly, the present studies permit us to characterize for the first time changes in the release of bioactive and immunoactive $\mathrm{LH}$, when the endogenous GNRH signal is amplified by opiate-receptor blockade.

Blockade of opiate receptors with the potent, selective and long-acting (half-time $\simeq 10.3 \mathrm{~h}$ ) antagonist, naltrexone $(30,31)$, evoked a significant increase in mean
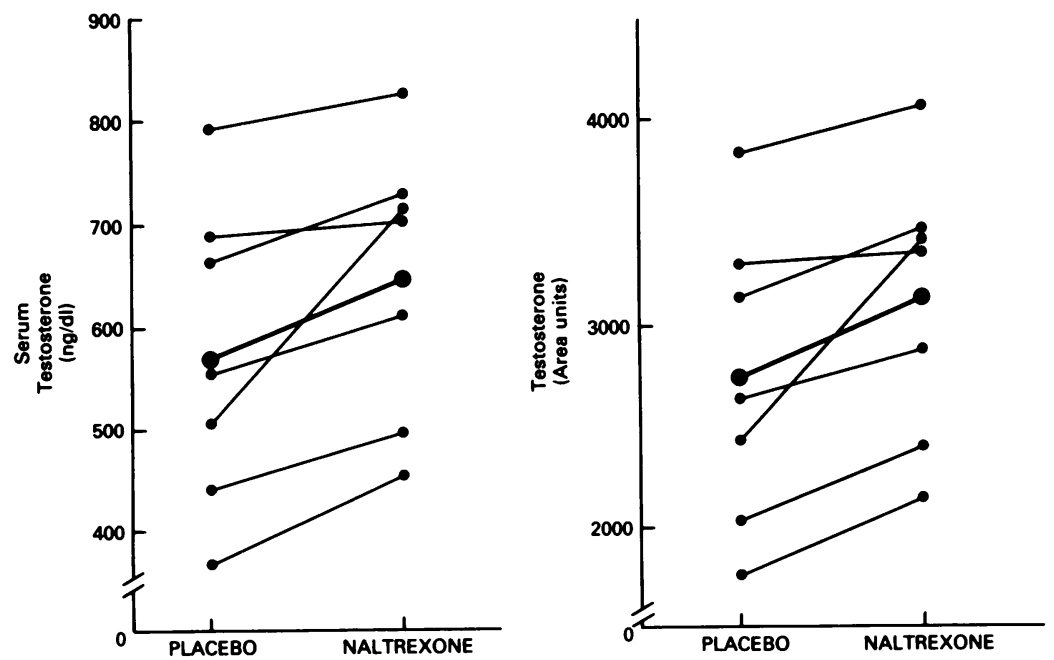

Figure 2 Mean (left) and integrated (right) serum concentrations of testosterone are given for seven individual men after placebo or naltrexone administration. Each mean derives from 25 samples drawn at 20 -min intervals over $8 \mathrm{~h}$ of study. The integrated concentrations over the $8 \mathrm{~h}$ of sampling were determined by the method of Santen and Bardin (28). 
and integrated serum concentrations of bioactive $\mathrm{LH}$ with continuation of the pulsatile pattern of $\mathrm{LH}$ secretion. Absence of any discernible opiate agonist action was confirmed by demonstrating no change in mean serum prolactin concentrations (32, and this study). The increase in bioactive $\mathrm{LH}$ concentrations was associated with a proportionate increase in immunoactive LH levels, so that mean bioactive:immunoactive LH ratios derived over the entire period of venous sampling did not change in response to naltrexone. Since naltrexone was devoid of effect in the RICT bioassay in vitro, and is not considered to alter hormone clearance in vivo, we believe that the major increase in serum concentrations of bioactive $\mathrm{LH}$ in response to naltrexone administration reflects an actual augmentation of secretion of biologically active LH molecules (discussed further below).

The higher mean and integrated serum concentrations of bioactive $\mathrm{LH}$ in the presence of an opiatereceptor antagonist were accompanied by a significantly increased number of bioactive LH pulses in all eight men. This increase was demonstrable by two different pulse-detection methods $(5,26)$, whose results agreed by $83 \%$. Since the pituitary gland is devoid of any intrinsic periodicity of $\mathrm{LH}$ release (6), the observed enhancement in bioactive $\mathrm{LH}$ pulse frequency must reflect an amplification of the endogenous GNRH signal. A similar conclusion has been reached from analyses of immunoactive LH pulses (21). However, immunoactive and bioactive LH pulses are sometimes discordant, possibly reflecting variations in the degree of glycosylation or other potency properties of the LH molecule released or cleared in vivo (33-35). The present work significantly extends prior reports on immunoactive LH pulsations by demonstrating for the first time, in any species, that brain opiate systems that modulate endogenous GNRH mechanisms are actually coupled to the effective secretion of biologically active $\mathrm{LH}$.

Analyses of the naltrexone-associated pulses of bioactive $\mathrm{LH}$ reveal that these pulses are rich in bioactivity, containing significantly increased bioactive:immunoactive $\mathrm{LH}$ ratios compared with interpulse base-line ratios. The degree of increase in bioactive:immunoactive ratios within LH pulses after naltrexone administration is quantitatively similar to that observed in spontaneous $\mathrm{LH}$ pulses that occur at a lower frequency. Thus, modulating the frequency of the endogenous GNRH signal (at least within this physiological range of pulse frequencies) provides one hypothalamic mechanism by which to control net pituitary release of $\mathrm{LH}$ molecules that retain high biological activity. Our inference that the frequency of endogenously generated GNRH pulses is an important modulator of circulating concentrations of bioactive $\mathrm{LH}$ is in accord with several previous studies that have documented changes in immunoactive $\mathrm{LH}$ pulse frequency in diverse conditions of health and disease $(1-12,27$, $36-39$ ). Moreover, our inference is congruent with the recent report that serum concentrations of bioactive LH increase strikingly in the spontaneous or induced preovulatory phase of the menstrual cycle in the rhesus monkey $(40,41)$ at a time when immunoactive $\mathrm{LH}$ pulse frequency increases $(2,5-7,9)$. Similar physiological alterations in bioactive $\mathrm{LH}$ secretion in normally cycling women have been observed and correlated with increased pulse frequency in the late follicular phase (42).

The observed increase in pulsatile bioactive LH secretion after naltrexone administration was associated with a corresponding significant rise in absolute peak bioactive LH concentrations within pulses. Neither the fractional amplitude (percentage above interpulse nadir, reference 28) nor the incremental amplitude (milli International Units per milliliter above interpulse base line, reference 27) was increased after naltrexone. These observations are consistent with a rise in interpulse concentrations of bioactive $\mathrm{LH}$ in response to naltrexone. Such increases in interpulse hormone concentrations could reflect either release of larger quantities of bioactive LH within each pulse (producing the observed, higher peak LH concentration in blood), or the demonstrated occurrence of more frequent pulses, with interpulse intervals that are consequently shorter (and hence allow less metabolic clearance of bioactive $\mathrm{LH}$ ), or both.

The increase in pulsatile secretion of bioactive $\mathrm{LH}$ was also associated with a significant increase in mean and integrated serum testosterone concentrations in these men. This observation provides important evidence that the apparent increase in bioactive $\mathrm{LH}$, as quantitated in the RICT assay in vitro, correctly reflects an actual increase in circulating concentrations of biologically effective $\mathrm{LH}$ in man in vivo. These findings are also consistent with earlier studies describing diminished serum testosterone concentrations in heroin and methadone users (43), and decreased androgen levels in male rats receiving opiate agonists chronically $(44,45)$. Moreover, in the human, more recent studies indicate that acute heroin administration suppresses serum testosterone levels, while chronic naltrexone administration increases mean testosterone concentrations (46). In the present work, we have demonstrated that opiate-receptor blockade with naltrexone acutely increases serum testosterone levels in normal men, and that this increase in androgen concentrations occurs pari passu with augmented pulsatile release of bioactive LH.

Our data do not permit us to ascertain whether the increase in mean serum testosterone concentrations 
represents a response to the increase in $\mathrm{LH}$ pulse frequency or pulse amplitude, or perhaps to the consequent increase in mean and interpulse concentrations of biologically active LH. However, in the ram, bull, rat, monkey, and peri-pubertal or, in occasional cases, in the adult human, episodic increases in immunoactive LH concentrations have been correlated with subsequent presumptive pulses of testosterone secretion (8, 47-58). In the present work, we found $3.5 \pm 1.0$ statistically significant fluctuations in serum testosterone concentrations per $8 \mathrm{~h}$. Nonetheless, we cannot make any definitive inference that these represent true "pulses" of testosterone release. In addition, we believe that the relatively high frequency of spontaneous and naltrexone-stimulated pulsations of bioactive (or immunoactive) $\mathrm{LH}$ in adult male subjects precludes defining a facile one-to-one correspondence between individual bioactive (or immunoactive) LH peaks and fluctuating testosterone concentrations. Further investigations using the in vitro RICT bioassay to quantitate effective circulating $\mathrm{LH}$ concentrations in subjects in whom the frequency and amplitude of bioactive LH pulses are manipulated selectively would be likely to clarify the exact nature of the pulsatile bioactive LH signal that is most effective in stimulating Leydig cell steroidogenesis.

In summary, we conclude that brain neuroendocrine mechanisms, such as the endogenous opiate system studied here, which are capable of controlling the pulsatile character of $\mathrm{LH}$ release can thereby significantly regulate the secretion of $\mathrm{LH}$ species enriched in bioactivity. Acute changes in circulating quantities of bioactive LH, quantitated by the sensitive and specific RICT assay in vitro, are also reflected in corresponding changes in testosterone concentrations in normal men in vivo. Thus, the in vitro bioassay of $\mathrm{LH}$ is likely to provide an important investigative tool to ultimately clarify the exact nature of the pulsatile bioactive $\mathrm{LH}$ signal that is most effective in enhancing trophic and steroidogenic functions of the gonad in health and disease.

\section{ACKNOWLEDGMENTS}

We are grateful for the expert technical support of $M$. A. Serabian, and our nurses and assistants in the Clinical Research Center and the laboratory, the skillful preparation of the manuscript by Maureen Schandert, and the provision of certain reagents for the $\mathbf{L H}$ assay by the National Institute of Arthritis, Metabolism, and Digestive Diseases, National Institute of Health, Bethesda, MD. We thank Dr. Richard J. Santen (Pennsylvania State University Medical College) and Dr. Robert A. Steiner (University of Washington School of Medicine) for providing their computer programs for pulse analysis.

This research was supported in part by U.S. Public Health Service General Clinical Research Grant RR-847 and by the Diabetes Research and Training Center grant 5 P60 AM 22125-05.

\section{REFERENCES}

1. Dierschke, D. J., A. N. Bhattacharya, L. E. Atkinson, and E. Knobil. 1970. Circhoral oscillations of plasma LH levels in the ovariectomized rhesus monkey. Endocrinology. 87:850-853.

2. Midgley, A. R., Jr., and R. B. Jaffe. 1971. Regulation of human gonadotropins. X. Episodic fluctuation of luteinizing hormone during the menstrual cycle. J. Clin. Endocrinol. Metab. 33:962-970.

3. Yen, S. S. C., C. C. Tsai, F. Naftolin, G. VandenBerg, and L. Ajabor. 1972. Pulsatile patterns of gonadotropin release in subjects with and without ovarian function. $J$. Clin. Endocrinol. Metab. 34:671-676.

4. Gay, V. L., and N. A. Sheth. 1972. Evidence for a periodic release of $\mathrm{LH}$ in castrated male and female rats. $E n$ docrinology. 90:158-163.

5. Santen, R. J., and C. W. Bardin. 1973. Episodic luteinizing hormone secretion in man. Pulse analysis, clinical interpretation, and pathological mechanisms. J. Clin. Invest. 52:2617-2628.

6. Knobil, E. 1980. The neuroendocrine control of the menstrual cycle. Recent Progr. Horm. Res. 36:53-74.

7. Naftolin, F., S. S. C. Yen, D. Perlman, C. C. Tsai, D. C. Parker, and T. Vargo. 1973. Nocturnal patterns of serum gonadotropins during the menstrual cycle. J. Clin. Endocr. Metab. 37:6-11.

8. Ellis, G. B., and C. Desjardins. 1982. Male rats secrete luteinizing hormone and testosterone episodically. Endocrinology. 110:1618-1623.

9. Backstrom, C. T., A. S. McNeilly, R. M. Leask, and D. T. Baird. 1982. Pulsatile secretion of LH, FSH, prolactin, oestradiol and progesterone during the human menstrual cycle. Clin. Endocrinol. 17:29-34.

10. Dufau, M. L., J. D. Veldhuis, F. Fraioli, M. L. Johnson, and I. Z. Beitens. 1983. Mode of secretion of bioactive luteinizing hormone in man. J. Clin. Endocrinol. Metab. 57:993-1000.

11. Clarke, I. J., and J. T. Cummins. 1982. The temporal relationship between gonadotropin releasing hormone (GnRH) and luteinizing hormone (LH) secretion in ovariectomized ewes. Endocrinology. 111:1737-1740.

12. Levine, J. E., K.-Y. F. Pau, V. D. Ramirez, and G. L. Jackson. 1982. Simultaneous measurement of luteinizing hormone-releasing hormone and luteinizing hormone release in unanesthetized, ovariectomized sheep. Endocrinology. 111:1449-1455.

13. Naor, Z., M. Katikineni, E. Loumaye, A. G. Vela, M. L. Dufau, and K. J. Catt. 1982. Compartmentalization of luteinizing hormone pools: dynamics of gonadotropin releasing hormone action in superfused pituitary cells. Mol. Cell. Endocrinol. 27:213-219.

14. Dufau, M. L., I. Z. Beitins, J. W. McArthur, and K. J. Catt. 1976. Effects of luteinizing hormone releasing hormone (LHRH) upon bioactive and immunoreactive serum LH levels in normal subjects. J. Clin. Endocrinol. Metab. 43:658-665.

15. Beitins, I. Z., M. L. Dufau, K. O'Loughlin, K. J. Catt, and J. W. McArthur. 1977. Analysis of biological and immunological activities in the two pools of $\mathrm{LH}$ released during constant infusion of luteinizing hormone-releasing hormone (LHRH) in men. J. Clin. Endocrinol. Metab. 45:605-611.

16. Cicero, T. J., C. E. Wilcox, R. D. Bell, and E. R. Meyer. 1980. Naloxone-induced increases in serum luteinizing hormone in the male: mechanisms of action. J. Pharmacol. Exp. Ther. 212:573-578.

17. Blank, M. S., and D. L. Roberts. 1982. Antagonist of 
gonadotropin-releasing hormone blocks naloxone-induced elevations in serum luteinizing hormone. Neuroendocrinology. 35:309-314.

18. Wilkes, M. M., and S. S. C. Yen. 1980. Augmentation by naloxone of efflux of GnRH from superfused medial basal hypothalamus. Life Sci. 28:2355-2360.

19. Ropert, J. F., M. E. Quigley, and S. S. C. Yen. 1981. Endogenous opiates modulate pulsatile luteinizing hormone release in humans. J. Clin. Endocr. Metab. 52:583588.

20. Sylvester, P. W., D. A. Van Vugt, C. F. Asylworth, E. A. Hanson, and J. Meites. 1982. Effects of morphine and naloxone on inhibition by ovarian hormones of pulsatile release of $\mathrm{LH}$ in ovariectomized rats. Neuroendocrinology. 34:269-274.

21. Ellingboe, J., J. D. Veldhuis, J. H. Mendelson, J. C. Kuehnle, and N. K. Mello. 1982. Effects of endogenous opioid blockade on the amplitude and frequency of pulsatile LH secretion in normal men. J. Clin. Endocrinol. Metab. 54:854-856.

22. Odell, W., G. T. Ross, and P. L. Rayford. 1967. Radioimmunoassay for luteinizing hormone in human plasma or serum: physiological studies. J. Clin. Invest. 46:248-256.

23. Dufau, M. L., R. Pock, A. Neubauer, and K. J. Catt. 1976. In vitro bioassay of $\mathrm{LH}$ in human serum: the interstitial cell testosterone (RICT) assay. J. Clin. Endocrinol. Metab. 42:958-968.

24. Solano, A. R., M. L. Dufau, and K. J. Catt. 1979. Bioassay and radioimmunoassay of serum luteinizing hormone in the male rat. Endocrinology. 105:372-381.

25. Abraham, G. E. 1974. Radioimmunoassay of steroids in biological material. Acta Endocrinol. 75(Suppl 183):719.

26. Clifton, D. K., and R. A. Steiner. 1983. Cycle detection: a technique for estimating the frequency and amplitude of episodic fluctuations in blood hormone and substrate concentrations. Endocrinology. 112:1057-1064.

27. Steiner, R. A., W. J. Bremner, and D. K. Clifton. 1982. Regulation of luteinizing hormone pulse frequency and amplitude by testosterone in the adult male rat. Endocrinology. 111:2055-2061.

28. Santen, R. J., and C. W. Bardin. 1973. Episodic luteinizing hormone secretion in man, pulse analysis, clinical interpretation, physiologic mechanisms. J. Clin. Invest. 52:2617-2628.

29. Winer, B. J. 1971. Statistical Principles in Experimental Design. McGraw-Hill, New York.

30. Julius, D. A. 1979. Research and development of naltrexone: a new narcotic antagonist. Am. J. Psychiatry. 136:782-786.

31. Verebey, K., S. J. Volavka, S. J. Mule, and R. B. Resnick. 1976. Naltrexone: disposition, metabolism, and effects after acute and chronic dosing. Clin. Pharmacol. Therapeutics. 20:315-328.

32. Ellingboe, J., J. H. Mendelson, and J. C. Kuehnle. 1980. Effects of heroin and naltrexone on plasma prolactin levels in man. Pharmacol. Biochem. Behav. 12:163-165.

33. Dufau, M. L., K. J. Catt, and T. Tsuruhara. 1971. Retention of biological activities by desialylated human luteinizing hormone and chorionic gonadotropin. Biochem. Biophys. Res. Comm. 44:1022-1026.

34. Tsuruhara, T., M. L. Dufau, G. Hickman, and K. J. Catt. 1972. Biological properties of HCG after removal of terminal sialic acid and galactose residues. Endocrinology. 91:296-301.

35. Reddy, P. V., and K. M. J. Menon. 1981. Existence of multiple molecular forms of luteinizing hormone in the rat: differences in immunological and biological activities between stored and circulating forms. Acta Endocrinol. 97:33-41.

36. McNeilly, A. S., M. O'Connell, and D. T. Baird. 1982. Induction of ovulation and normal luteal function by pulsed injections of luteinizing hormone in anestrous ewes. Endocrinology. 110:1292-1297.

37. Levine, J. E., and V. D. Ramirez. 1982. Luteinizing hormone-releasing hormone release during the rat estrous cycle and after ovariectomy, as estimated with push-pull cannulae. Endocrinology. 111:1439-1444.

38. Goodman, R. L., E. L. Bittman, D. L. Foster, and F. J. Karsch. 1982. Alterations in the control of luteinizing hormone pulse frequency underlie the seasonal variation in estradiol negative feedback in the ewe. Biol. Reprod. 27:580-586.

39. Jakacki, R., R. P. Kelch, S. E. Sauder, J. S. Lloyd, N. J. Hopwood, and J. C. Marshall. 1982. Pulsatile secretion of luteinizing hormone in children. J. Clin. Endocrinol. Metab. 55:453-457.

40. Dufau, M. L., G. D. Hodgen, A. L. Goodman, and K. J. Catt. 1977. Bioassay of circulating luteinizing hormone in the Rhesus monkey: comparison with radioimmunoassay during physiological changes. Endocrinology. 100:1557-1562.

41. Marut, E. L., R. F. Williams, B. D. Cowan, A. Lynch S. P. Lerner, and G. D. Hodgen. 1981. Pulsatile pituitary gonadotropin secretion during maturation of the dominant follicle in monkeys: estrogen positive feedback enhances the biological activity of LH. Endocrinology. 109:2270-2272.

42. Veldhuis, J. D., I. Z. Beitins, M. L. Johnson, M. A. Serabian, and M. L. Dufau. 1984. Biologically active leuteinizing hormone is secreted in episodic pulsations that vary in relation to stage of the menstrual cycle. J. Clin. Endocrinol. Metab. In press.

43. Azzizi, F., A. G. Vagenakis, C. Longcope, S. H. Ingbar, and L. E. Veaverman. 1973. Decreased serum testosterone concentration in male heroin and methadone addicts. Steroids. 22:467-470.

44. Cicero, T. J., E. R. Meyer, W. G. Wiest, J. W. Onley, and R. D. Bell. 1975. Effects of chronic morphine administration on the reproductive system of the male rat. J. Pharmacol. Exp. Ther. 192:542-548.

45. Cicero, T. J., E. R. Meyer, and R. D. Bell. 1976. Effects of morphine and methadone on serum testosterone and LH levels and on the secondary sex organs of the male rat. Endocrinology. 98:367-371.

46. Mendelson, J. H., J. Ellingboe, J. C. Kuehnle, and N. K. Mello. 1980. Heroin and naltrexone effects on pituitarygonadal hormones in man: interaction of steroid feedback effects, tolerance and supersensitivity. J. Pharmacol. Exp. Ther. 214:503-507.

47. Naftolin, F., S. S. C. Yen, and C. C. Tsai. 1972. Rapid cycling of plasma gonadotropins in normal men as demonstrated by frequent sampling. Nature New Biol. 236:92-98.

48. Nankin, H. R., and P. Troen. 1971. Repetitive luteinizing hormone elevations in serum of normal men. J. Clin. Endocrinol. Metab. 33:558-563.

49. Bardin, C. W., G. T. Ross, and M. B. Lipsett. 1967. Site of action of clomiphene citrate in men: a study of the pituitary-Leydig cell axis. J. Clin. Endocrinol. Metab. 27:1558-1564

50. Boyar, R. M., R. S. Rosenfield, S. Kapen, J. W. Finkelstein, H. P. Roffward, E. D. Weitzman, and L. Hellman. 1974. 
Simultaneous augmented secretion of luteinizing hormone and testosterone during sleep. J. Clin. Invest. 54:609-615.

51. Naftolin, H., L. Judd, and S. S. Yen. 1973. Pulsatile patterns of gonadotropins and testosterone in man: the effects of Clomiphene with and without testosterone. $J$. Clin. Endocrinol. Metab. 36:285-290.

52. Judd, H. L., D. C. Parker, T. M. Siler, and S. S. C. Yen. 1974. The nocturnal rise of plasma testosterone in pubertal boys. J. Clin. Endocrinol. Metab. 38:710-714.

53. Katangole, C. B., F. Naftolin, and R. V. Short. 1971. Relationship between blood levels of luteinizing hormone and testosterone in bulls, and the effects of sexual stimulation. J. Endocrinol. 50:457-461.

54. Schanbacher, D. B., and M. J. D'Occhio. 1982. Validation of a direct radioimmunoassay for testosterone in unextracted serum from five species: application to study of hypothalamic-pituitary gonadal axis in males. J. Androl. 3:45-49.
55. de la Torre, B., B. Sjoberg, M. Hedman, G. Bartfai, and E. Diczfalusy. 1981. A study of the short-time variation and interrelationship of plasma hormone levels reflecting pituitary, adrenocortical and testicular function in fertile men. Int. J. Androl. 4:532-538.

56. Rowe, P. H., P. A. Racey, G. A. Lincoln, M. Ellwood, J. Lehane, and J. C. Shenton. 1975. The temporal relationship between the secretion of luteinizing hormone and testosterone in man. J. Endocrinol. 64:17-22.

57. Plant, T. M. 1981. Time courses of concentrations of circulating gonadotropin, prolactin, testosterone, and cortisol in adult male rhesus monkeys (Macaca mulatta) throughout the $24 \mathrm{~h}$ light-dark cycle. Biol. Reprod. 25:244-248.

58. Ellis, G. B., and C. Desjardins. 1982. Male rats secrete luteinizing hormone and testosterone episodically. Endocrinology. 110:1618-1624. 